\title{
Learning from the dead: improving safety while placing unconscious trauma patients in various lateral positions
}

\author{
Per Kristian Hyldmo ${ }^{1,2^{*}}$, Bryan P Conrad ${ }^{3}$, Dewayne N Dubose ${ }^{3}$, Jo Røislien ${ }^{1,6}$, Mark Prasarn ${ }^{4}$, Eldar Søreide ${ }^{2,7}$, \\ Glenn Rechtine ${ }^{5}$, MaryBeth Horodyski ${ }^{3}$
}

From London Trauma Conference 2013

London, UK. 10-13 December 2013

\section{Background}

The unconscious trauma patient with a possible unstable spinal injury constitutes a clinical challenge. To protect the unintubated airway, some guidelines [1,2] recommend that the patient be turned into a lateral position, e.g. the Recovery Position (RP) [1] or the Lateral Trauma Position (LTP) [2]. Other lateral positions have also been proposed, as the HAINES position [3] and variations thereof. However, moving the patient may cause secondary neurological injury. The aim of this study was to explore how much motion lateral position techniques produce in an unstable cervical spine injury.

\section{Method}

We surgically created a global ligamentous instability between $\mathrm{C} 5$ and $\mathrm{C} 6$ in five fresh cadavers [4]. Four different techniques were evaluated; RP, LTP and two varieties of HAINES (one or both legs flexed; H1 and H2). Relative angular and linear motion between $\mathrm{C} 5$ and $\mathrm{C} 6$ was measured using an electromagnetic tracking device (Liberty, Polhemus Inc. ${ }^{\mathrm{TM}}$, Colchester, VT). Each method was repeated tree times in each cadaver. Both angular and linear movements were measured. Data were analysed using generalized linear mixed models (GLMM), adjusting for intra-cadaver correlation.

\section{Results}

Compared to RC, LTP created significantly less movement during lateral bending $(\mathrm{p}=.037)$, while $\mathrm{H} 1$ and $\mathrm{H} 2$ had significantly less movement than $\mathrm{RC}$ in axial translation ( $\mathrm{p}=.009$ and .033). There was a tendency towards

${ }^{1}$ Research Department, Norwegian Air Ambulance Foundation, Drøbak,

Norway

Full list of author information is available at the end of the article
LTP and $\mathrm{H} 1$ and $\mathrm{H} 2$ performing better than $\mathrm{RC}$ also for other movements.

\section{Conclusion}

Our results indicate that in unconscious trauma patients, LTP or one of the two HAINES techniques is preferable to the classic recovery position in the setting of an unstable cervical spine injury.

\begin{abstract}
Authors' details
${ }^{1}$ Research Department, Norwegian Air Ambulance Foundation, Drøbak, Norway. ${ }^{2}$ Network for Medical Sciences, University of Stavanger, Stavanger, Norway. ${ }^{3}$ Department of Orthopaedics \& Rehabilitation, University of Florida, Gainesville, Florida, USA. ${ }^{4}$ Department of Orthopaedics, University of Texas, Huston, Texas, USA. ${ }^{5}$ Associate Chief of Staff, Bay Pines VAHCS, St. Petersburg, Florida, USA. ${ }^{6}$ Department of Biostatistics, University of Oslo, Oslo, Norway. ${ }^{7}$ Department of Anaesthesiology and Intensive Care, Stavanger University Hospital, Stavanger, Norway.
\end{abstract}

Published: 7 July 2014

\section{References}

1. Deakin CD, et al: European Resuscitation Council Guidelines for Resuscitation 2010 Section 4. Adult advanced life support. Resuscitation 2010, 81:1305-1352.

2. Berlac $P$, et al: Pre-hospital airway management: guidelines from a task force from the Scandinavian Society for Anaesthesiology and Intensive Care Medicine. Acta Anaesthesiol Scand 2008, 52:897-907.

3. Haines J: Positioning an unconscious patient with suspected neck injury. JEMS: Journal of Emergency Medical Services 1996, 21:85-85.

4. Horodyski M, et al: Cervical Collars are Insufficient for Immobilizing an Unstable Cervical Spine Injury. J Emerg Med 2011, 41(5):513-519.

\section{doi:10.1186/1757-7241-22-S1-04}

Cite this article as: Hyldmo et al: Learning from the dead: improving safety while placing unconscious trauma patients in various lateral positions. Scandinavian Journal of Trauma, Resuscitation and Emergency Medicine 2014 22(Suppl 1):04.
() Biomed Central

(c) 2014 Hyldmo et al; licensee BioMed Central Ltd. This is an Open Access article distributed under the terms of the Creative Commons Attribution License (http://creativecommons.org/licenses/by/4.0), which permits unrestricted use, distribution, and reproduction in any medium, provided the original work is properly cited. The Creative Commons Public Domain Dedication waiver (http:// creativecommons.org/publicdomain/zero/1.0/) applies to the data made available in this article, unless otherwise stated. 